\title{
Delayed-onset endophthalmitis associated with corneal suture infections
}

\author{
Christopher R Henry ${ }^{1 *}$, Harry W Flynn Jr ${ }^{1}$, Darlene Miller ${ }^{1}$, Amy C Schefler ${ }^{2}$, Richard K Forster ${ }^{1}$ \\ and Eduardo C Alfonso ${ }^{1}$
}

\begin{abstract}
Background: The purpose of the current study was to report the microbiology, risk factors, and treatment outcomes in patients with delayed-onset endophthalmitis associated with corneal suture infections. For this retrospective consecutive case series, a search of the ocular microbiology department database was performed to identify all patients with positive corneal and intraocular cultures (anterior chamber and/or vitreous) between 01 January 1995 and 01 January 2010. A subset of patients with a history of corneal suture infections and delayed-onset endophthalmitis was identified.
\end{abstract}

Results: Over the 15-year period of the study, 68 patients were identified to have both positive corneal and intraocular cultures. Among them, six patients were identified to have a culture-proven, delayed-onset endophthalmitis that developed from a culture-positive corneal suture infection. All of the patients in the current study were using topical corticosteroids at the time of diagnosis. In four of six patients, there was documented manipulation of a suture before the development of endophthalmitis. Streptoccocus was identified as the causative organism in five of six patients in the current study. All of the Streptoccocus isolates were sensitive to vancomycin. The single case of Serratia marcescens endophthalmitis was sensitive to amikacin, ceftazidime, ciprofloxacin, gentamicin, and tobramycin. Treatment modalities varied and were guided by the attending ophthalmologist depending upon clinical presentation. One patient with severe Streptococcus pyogenes keratitis and endophthalmitis underwent a primary enucleation after developing a wound dehiscence. Of the remaining five patients, all received topical and intravitreal antibiotics. Therapeutic penetrating keratoplasty was performed in three patients. Pars plana vitrectomy was performed in two patients. Visual acuity outcomes ranged from 20/150 to no light perception.

Conclusions: In the current study, Streptococcus was isolated in nearly all patients with delayed-onset endophthalmitis associated with corneal suture infections. Topical steroid use and suture manipulation were identified as associated factors for developing endophthalmitis. Visual acuity outcomes were poor despite the prompt recognition of endophthalmitis and appropriate antibiotic therapy.

Keywords: Endophthalmitis, Corneal sutures, Suture abscess, Infectious keratitis, Streptococcus

\section{Background}

Corneal suture-related complications, particularly following penetrating keratoplasty, are well-known. Reported hazards of corneal sutures include suture erosions, sterile corneal infiltrates, and infectious keratitis, among others [1-6]. Additionally, there are risks associated with corneal suture removal including wound leakage, wound dehiscence, astigmatic changes, and even graft rejection [1-6].

\footnotetext{
* Correspondence: chenry2@med.miami.edu

'Department of Ophthalmology, Bascom Palmer Eye Institute, University of Miami Miller School of Medicine, 900 NW 17th Street, Miami, FL 33136, USA Full list of author information is available at the end of the article
}

Despite this, relatively few cases of corneal suture-related endophthalmitis have been reported in the literature [7-12].

The purpose of the current study is to describe a consecutive series of patients with delayed-onset endophthalmitis associated with corneal suture infections and to report the associated microbiology, risk factors, and treatment outcomes in these patients.

\section{Methods}

Institutional Review Board approval was obtained from the University of Miami Miller School of Medicine Sciences 
Subcommittee for the Protection of Human Subjects. For this retrospective consecutive case series, a search of the ocular microbiology department database was performed to identify all patients with positive corneal and intraocular cultures between 01 January 1995 and 01 January 2010. Medical records were further reviewed to identify a subset of patients with a history of corneal suture infection that later developed endophthalmitis. To be included in the current study, patients were required to have positive corneal cultures from a suture infection or suture abscess and positive intraocular cultures from fluid from the anterior chamber and/or vitreous. The same organism was required to be positive from both corneal and intraocular cultures. Endophthalmitis was defined by the presence of severe intraocular inflammation as well as positive intraocular cultures. The current study represents a subgroup analysis of a previously reported consecutive series on keratitisassociated endophthalmitis [8].

All corneal cultures in the current study were obtained via corneal scraping along the involved suture site and were plated directly onto several different culture media, including chocolate agar, 5\% sheep blood agar, and Sabouraud agar. All anterior chamber cultures in the current study were obtained at the time of penetrating keratoplasty. Vitreous cultures were obtained either at the time of vitreous tap and inject or during pars plana vitrectomy. Sutures were sent for cultures in selected cases. Specimens underwent incubation as described previously by our group [8]. All cultures were read and classified by Ocular Microbiology Department staff. Antibiotic sensitivities were performed on all grampositive and gram-negative bacteria.

After analyzing the microbiology records, the corresponding medical records were reviewed on all study patients. Clinical risk factors and treatment outcomes were assessed.

\section{Results and discussion \\ Results}

Over the 15-year period of the study, 68 patients were identified to have both positive corneal and intraocular cultures (anterior chamber and/or vitreous). Of these, six patients were identified to have a culture-proven, delayed-onset endophthalmitis that developed from a culture-positive corneal suture infection.

The mean age of patients in the current series was 66.0 years (range, 36 to 74 ). Three patients were men, and three patients were women. A summary of each patient is provided in Table 1, and representative figures are shown in Figure 1. Five patients had a suture infections related to a previous penetrating keratoplasty wound, and one patient has a suture infection related to

Table 1 Demographics and clinical features of patients with corneal suture-related endophthalmitis

\begin{tabular}{|c|c|c|c|c|c|c|}
\hline Case number & 1 & 2 & 3 & 4 & 5 & 6 \\
\hline Sex/age (years) & Female, 71 & Male, 70 & Female, 36 & Male, 72 & Female, 73 & Male, 74 \\
\hline Year & 1996 & 1997 & 1999 & 2004 & 2007 & 2009 \\
\hline Prior surgery & PKP & PKP & PKP & PKP & PKP & CE.IOL \\
\hline Location of suture abscess & Inferonasal & Superotemporal & Superotemporal & Superotemporal & Superotemporal & Superotemporal \\
\hline Suture technique & Running & Interrupted & Interrupted & Running & Interrupted & Interrupted \\
\hline Responsible organism & $\begin{array}{l}\text { Streptococcus } \\
\text { pyogenes }\end{array}$ & $\begin{array}{l}\text { Streptococcus } \\
\text { pneumoniae }\end{array}$ & $\begin{array}{l}\text { Streptococcus } \\
\text { pneumoniae }\end{array}$ & $\begin{array}{l}\text { Streptococcus } \\
\text { agalactiae }\end{array}$ & $\begin{array}{l}\text { Streptococcus } \\
\text { salivarius }\end{array}$ & $\begin{array}{l}\text { Serratia } \\
\text { marcescens }\end{array}$ \\
\hline Cornea culture result & Positive & Positive & Positive & Positive & Positive & Positive \\
\hline Suture culture result & Not performed & Not performed & Not performed & Not performed & Positive & Positive \\
\hline Anterior chamber culture result & Not performed & Not performed & Positive & Positive & Not performed & Not performed \\
\hline Vitreous culture result & Positive & Positive & Not performed & Not performed & Positive & Positive \\
\hline $\begin{array}{l}\text { Contributing mechanism to suture abscess } \\
\text { and endophthalmitis }\end{array}$ & $\begin{array}{l}\text { Loose suture } \\
\text { manipulated }\end{array}$ & $\begin{array}{l}\text { Loose suture } \\
\text { removed }\end{array}$ & None identified & $\begin{array}{l}\text { Broken running } \\
\text { suture }\end{array}$ & $\begin{array}{l}\text { Loose suture } \\
\text { removed }\end{array}$ & None identified \\
\hline $\begin{array}{l}\text { Time from prior surgery to suture abscess } \\
\text { diagnosis }\end{array}$ & 59 days & 1,324 days & 713 days & 873 days & 365 days & 58 days \\
\hline $\begin{array}{l}\text { Time from suture manipulation or } \\
\text { complication to endophthalmitis diagnosis }\end{array}$ & 5 days & 5 days & NA & 4 days & 57 days & NA \\
\hline Topical steroid use at presentation & $\begin{array}{l}\text { Prednisolone } \\
\text { acetate 1\% qid }\end{array}$ & $\begin{array}{l}\text { Prednisolone } \\
\text { acetate 1\% tid }\end{array}$ & $\begin{array}{l}\text { Prednisolone } \\
\text { acetate } 1 \% \text { q1h }\end{array}$ & $\begin{array}{l}\text { Prednisolone } \\
\text { acetate } 1 \% \text { qid }\end{array}$ & $\begin{array}{l}\text { Prednisolone } \\
\text { acetate 1\% bid }\end{array}$ & $\begin{array}{l}\text { Prednisolone } \\
\text { acetate } 1 \% \text { qid }\end{array}$ \\
\hline Lens status & Pseudophakic & Pseudophakic & Pseudophakic & Pseudophakic & Pseudophakic & Pseudophakic \\
\hline Intact posterior capsule & Yes & Yes & Yes & No & No & No \\
\hline Corneal perforation & Yes & No & Yes & Yes & No & No \\
\hline
\end{tabular}




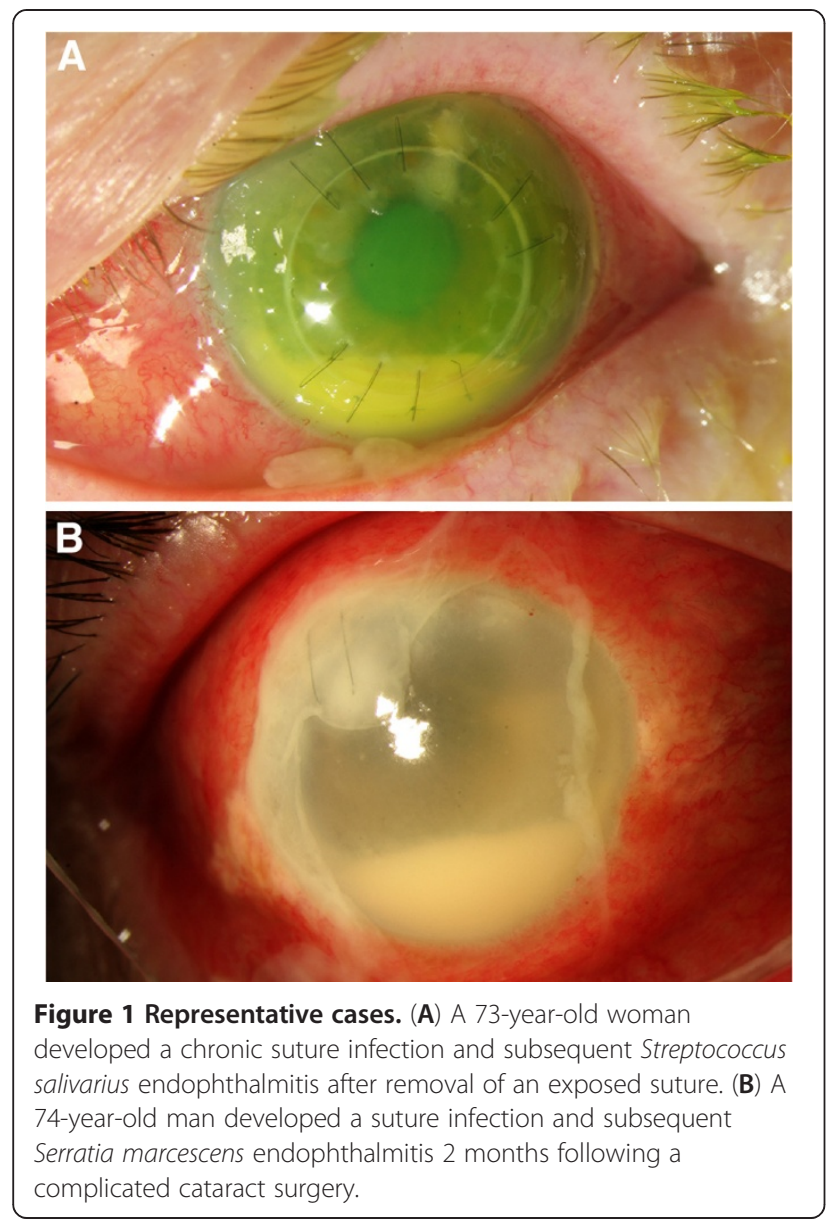

a corneal wound from a prior complicated cataract surgery that included a pars plana vitrectomy and intraocular lens placement in the ciliary sulcus. At the time of diagnosis, all patients were using topical prednisolone acetate $1 \%$, with the frequency ranging from hourly to twice daily. Three patients had a history of ocular surface disease. No patients were contact lens users, and no patients had a history of being immunocompromised. Potential contributing mechanisms that were temporally related to endophthalmitis included the removal of a loose or exposed suture (two patients), a broken running suture (one patient), and manipulation of a loose running suture (one patient). In each of these four patients, the corneal infiltrate was present at the time of suture removal or manipulation. One of these patients was not immediately started on topical antibiotics despite the presence of a corneal infiltrate and active manipulation of a suture. After presentation with a corneal infiltrate, topical prednisolone acetate $1 \%$ was continued at the same frequency in four patients, decreased in one patient, and stopped altogether in a final patient.

The average number or previous surgeries for all patients was 2.3 (range, 1 to 7 ). The mean length of time from most recent surgery to presentation with suture infection was 565.3 days (range, 58 to 1,324). In the four patients where there was documented manipulation of a suture or a broken suture, the mean length of time from incident to endophthalmitis diagnosis was 17.8 days (median, 5; range, 4 to 57$)$.

Clinical features at initial diagnosis included corneal infiltrate around an existing suture or previous suture (6/6 [100\%]), conjunctival injection (6/6 [100\%]), documented vitritis on clinical exam and/or echography $(5 / 6$ [83\%]), moderate to severe pain (5/6 [83\%]), and hypopyon (4/6 [67\%]). In the two patients with no documented hypopyon, there was noted to be a full thickness corneal infiltrate with an endothelial plaque and fibrin in the anterior chamber. A corneal perforation or wound dehiscence developed in three of six (50\%) study patients.

Streptoccocus was identified as the causative organism in five of six patients in the current study. All of the Streptoccocus isolates (5/5 [100\%]) were sensitive to vancomycin. The single case of Serratia marcescens endophthalmitis was sensitive to amikacin, ceftazidime, ciprofloxacin, gentamicin, and tobramycin. No cases of fungal suture infection-related endophthalmitis were identified during the 15-year study period.

Treatment modalities varied and were guided by the attending ophthalmologist depending upon clinical presentation and are shown in Table 2. One patient with severe Streptococcus pyogenes keratitis and endophthalmitis underwent a primary enucleation after developing a wound dehiscence. Of the remaining five patients, all received topical and intravitreal antibiotics. Therapeutic penetrating keratoplasty was performed in three patients. Pars plana vitrectomy was performed in two patients. Best corrected visual acuity outcomes at last examination were generally poor and ranged from 20/150 to no light perception.

\section{Discussion}

Previous studies have detailed potential complications of corneal sutures [1-6]. One large consecutive series by Christo et al. reviewed records of 361 corneal transplant grafts and reported a number of frequent suture-related complications following penetrating keratoplasty including: suture erosions (10.8\%), sterile corneal infiltrates $(9.4 \%)$, and loose sutures in need of surgical repair to prevent wound separation (8.3\%) [1]. An ulcerative epithelial defect and infiltrate involving a loose or broken suture developed in 12 grafts (3.3\%), but just one of these eyes progressed to endophthalmitis. Streptococcus isolates were the most commonly identified organism responsible for suture infections (5/12 patients). Similarly, Leahy et al. reported a series of 18 corneal suture abscesses developing after 773 penetrating keratoplasties (2.3\%) [2]. One of these eyes progressed to endophthalmitis after 
Table 2 Treatment strategies and outcomes in patients with corneal suture-related endophthalmitis

\begin{tabular}{|c|c|c|c|c|c|c|}
\hline Case number & 1 & 2 & 3 & 4 & 5 & 6 \\
\hline Presenting visual acuity & $L P$ & $20 / 200$ & $\mathrm{LP}$ & LP & $20 / 400$ & NLP \\
\hline $\begin{array}{l}\text { Management - topical } \\
\text { antibiotics }\end{array}$ & None & $\begin{array}{l}\text { Ceftazidime, } \\
\text { vancomycin }\end{array}$ & $\begin{array}{l}\text { Gentamicin, } \\
\text { vancomycin }\end{array}$ & $\begin{array}{l}\text { Cefazolin, moxifloxacin, } \\
\text { vancomycin }\end{array}$ & $\begin{array}{l}\text { Ceftazidime, moxifloxacin, } \\
\text { vancomycin }\end{array}$ & $\begin{array}{l}\text { Ceftazidime, } \\
\text { vancomycin }\end{array}$ \\
\hline $\begin{array}{l}\text { Management - intravitreal } \\
\text { antibiotics }\end{array}$ & None & Vancomycin & Vancomycin & Vancomycin & Ceftazidime, vancomycin & $\begin{array}{l}\text { Ceftazidime, } \\
\text { vancomycin }\end{array}$ \\
\hline $\begin{array}{l}\text { Management - intravitreal } \\
\text { steroids }\end{array}$ & No & Yes & No & No & Yes & Yes \\
\hline $\begin{array}{l}\text { Management - } \\
\text { penetrating keratoplasty }\end{array}$ & No & No & Yes & Yes & Yes & No \\
\hline Management - vitrectomy & No & Yes & No & No & Yes & No \\
\hline $\begin{array}{l}\text { Visual acuity at last follow- } \\
\text { up visit }\end{array}$ & $\begin{array}{l}\text { NLP/ } \\
\text { enucleated }\end{array}$ & LP & LP & $20 / 200$ & $20 / 150$ & NLP/enucleated \\
\hline
\end{tabular}

$L P$ light perception, NLP no light perception.

developing a wound separation related to the suture infection. Gram-positive isolates were cultured from 15 of 18 grafts developing a suture infection (83\%). Staphylococcus species were isolated from ten suture infections, and Streptococcus species were isolated from seven suture infections. In 13 of 18 patients, topical steroid use was identified as a possible risk factor for the development of a suture infection.

Another study by Siganos et al. investigated the microbial findings in patients with broken or loose sutures after penetrating keratoplasty [13]. The authors prospectively evaluated 55 eroded sutures in 35 eyes and found that 34 sutures were sterile (61.8\%) and 21 sutures had positive cultures for both Staphylococcus epidermidis and diptheroids (38.1\%). Interestingly, the authors did not report isolating Streptococcus species from any of these sutures. An infiltrate was found near 15 of 55 eroded sutures (27.2\%) but was less than $1 \mathrm{~mm}$ in size in all cases and only seven of the sutures were culture positive. Cultures were not performed on the corneal infiltrate in these cases, and no patients were reported to develop endophthalmitis or severe keratitis resulting in vision loss. Sutures eroded for $24 \mathrm{~h}$ or more before removal were statistically more likely to be culture positive in this study $(p=0.043)$.

To date, there have been few patients with corneal suturerelated endophthalmitis reported in the literature (Table 3) [7-12]. The series by Christo et al. and Leahy et al. highlighted the rarity of endophthalmitis developing from corneal suture-related infections [1,2]. Additionally, a literature search identified just two previous case series dedicated to the subject of corneal suture infection-related endophthalmitis $[7,12]$. Khurshid et al. reported a series of five cases of suspected endophthalmitis secondary to suture-related corneal infection [7]. This study was significantly different that the current study in that four patients in their series developed suture infections and endophthalmitis related to extracapsular cataract extraction and one patient developed a suture infection and endophthalmitis related to a corneal laceration repair. All patients in their series failed to improve on topical antimicrobial therapy alone but responded favorably to the administration of intravitreal vancomycin and amikacin. Visual acuity outcomes were very good, with two patients recovering 6/6 vision, one patient recovering 6/7.5 vision, and two patients recovering 6/12 vision. Positive cultures were recovered in two of the five patients, with gram-positive bacteria accounting for both cases (Streptococcus pneumoniae and Staphylococcus aureus). Additionally, Confino and Brown previously reported a series of three patients who developed bacterial endophthalmitis from a suture abscess [12]. Organisms responsible for endophthalmitis were Pseudomonas aeruginosa, Klebsiella oxytoca, and $S$. epidermidis. The authors identified loose or degraded sutures

Table 3 Reported cases of bacterial endophthalmitis from corneal suture infections

\begin{tabular}{lrrrr}
\hline First author & Confino & Leahey & Khurshid & $\begin{array}{r}\text { Current } \\
\text { study }\end{array}$ \\
\hline Year of publication & 1985 & 1993 & 2003 & 2013 \\
Number of reported cases & 3 & 1 & 5 & 6 \\
$\begin{array}{l}\text { Number of culture-positive } \\
\text { cases }\end{array}$ & 3 & 1 & 2 & 6 \\
$\begin{array}{l}\text { PKP-related suture infection } \\
\text { Cataract wound-related }\end{array}$ & $3 / 3$ & $1 / 1$ & $0 / 5$ & $5 / 6$ \\
suture infection & $0 / 3$ & $0 / 1$ & $4 / 5$ & $1 / 6$ \\
Gram-positive isolates & $1 / 3$ & $1 / 1$ & $2 / 2$ & $5 / 6$ \\
$\begin{array}{l}\text { Topical steroid use at } \\
\text { diagnosis }\end{array}$ & $2 / 3$ & $1 / 1$ & Not & $6 / 6$ \\
$\begin{array}{l}\text { Management - intravitreal } \\
\text { antibiotics }\end{array}$ & $1 / 3$ & $1 / 1$ & $5 / 5$ & $5 / 6$ \\
$\begin{array}{l}\text { Management - pars plana } \\
\text { vitrectomy }\end{array}$ & $1 / 3$ & $1 / 1$ & $0 / 5$ & $2 / 6$ \\
Last visual acuity $\geq 20 / 50$ & $0 / 3$ & $0 / 1$ & $5 / 5$ & $0 / 6$ \\
Last visual acuity $\geq 20 / 400$ & $2 / 3$ & $0 / 1$ & $5 / 5$ & $2 / 6$ \\
Enucleation or evisceration & $1 / 3$ & $0 / 1$ & $0 / 5$ & $2 / 6$ \\
\hline PKP pentrang keraplasty & & &
\end{tabular}

PKP penetrating keratoplasty. 
in all three cases as the principal source for the development of a suture infection and subsequent endophthalmitis. In this series, visual acuity outcomes were poor and ranged from 20/200 to no light perception.

The current study supports the fact that gram-positive bacteria account not only for the majority of cases of corneal suture-related infections but also corneal suture infection-related endophthalmitis. Additionally, while Staphylococcus species seem to be more commonly isolated from degraded sutures, it appears that Streptococcus species are more often responsible for severe suture infections and endophthalmitis. Furthermore, the current study supports the opinion that the development of endophthalmitis from a suture abscess is uncommon. Despite this fact, potentially modifiable risk factors were identified in all patients who developed endophthalmitis. In four patients, there was documented manipulation of a suture shortly before the development of endophthalmitis, including removal of a loose or exposed suture (two patients), a broken running suture (one patient), or manipulation of a loose running suture (one patient). Additionally, all six of the patients in the current study were using topical steroids, ranging from twice a day to hourly at the time of diagnosis of a suture abscess.

In a 2001 publication, the Royal College of Ophthalmologists recommend that corneal sutures be removed within 3 months following routine extracapsular cataract surgery, even though more recent versions of these guidelines have not provided specific recommendations [14]. Additionally, the decision to remove sutures after a penetrating keratoplasty can be a complex decision, particularly when refractive considerations are involved [15-17]. Regarding suture-related complications following penetrating keratoplasty, Christo et al. advocated the removal of penetrating keratoplasty sutures by 1 year in vascularized recipients and by 18 months in all patients [1]. Other authors have recommended that sutures from corneal grafts preferably be removed within 1 year of the operation or at discharge of patient care $[15,16]$. In the current study, three patients developed endophthalmitis from a corneal suture infection where the sutures that had been in place for over 2 years following the original surgery. Based on the findings in our study, we hypothesize that the long-term retention of corneal sutures after cataract surgery or penetrating keratoplasty could be a risk factor for endophthalmitis development, although this severe complication is very rare. Furthermore, it appears that prolonged steroid use in cases in which a corneal suture infection is present may increase the risk for progression to endophthalmitis. Alternatives to topical corticosteroids, such as cyclosporin A and/or suture removal should be considered when clinically appropriate. We recommend that topical povidone iodine drops be used prior to suture manipulation in all patients. Additionally, we recommend that patients be placed on topical antibiotic drops after suture manipulation or removal. Patients with infiltrates along corneal sutures should be monitored carefully.

\section{Conclusions}

Streptococcus infections accounted for nearly all cases of suture infection-related endophthalmitis in the current study. Topical steroid use and suture manipulation were identified as possible risk factors for developing endophthalmitis. Visual acuity outcomes were poor despite prompt recognition of endophthalmitis and appropriate antibiotic therapy.

\section{Competing interests}

HWF is a consultant for Santen, and ECA is an advisor for Bio-Tissue and receives grant/research support from Alcon, Allergan, and Bausch \& Lomb. $\mathrm{CRH}, \mathrm{DM}, \mathrm{ACS}$, and RKF declare that they have no competing interests.

\section{Authors' contributions}

$\mathrm{CRH}$ participated in study conception, study design, data collection, and drafting of the manuscript. HWF participated in study conception, study design, and drafting of the manuscript. DM is the microbiologist for the study and participated in data collection and critical revision of the manuscript. ACS participated in study conception, data collection, and critical revision of the manuscript. RKF participated in study conception and critical revision of the manuscript. ECA participated in critical revision of the manuscript. All authors read and approved the final manuscript.

\section{Acknowledgments}

This research was funded in part by an unrestricted grant from Research to Prevent Blindness Inc., New York, NY, USA, and the National Institutes of Health NEI Center Grant P30 EY014801.

\section{Author details}

${ }^{1}$ Department of Ophthalmology, Bascom Palmer Eye Institute, University of Miami Miller School of Medicine, 900 NW 17th Street, Miami, FL 33136, USA. ${ }^{2}$ Retina Consultants of Houston, Houston, TX 77030, USA.

Received: 20 April 2013 Accepted: 30 May 2013

Published: 11 June 2013

\section{References}

1. Christo CG, van Rooij J, Geerards AJM, Remeijer L, Beekhuis WH (2001) Suture-related complications following keratoplasty: a 5-year retrospective study. Cornea 20:816-819

2. Leahey AB, Avery RL, Gottsch JD, Mallette RA, Stark WJ (1993) Suture abscess after penetrating keratoplasty. Cornea 12:489-492

3. Huang SCM, Wu SC, Wu WC, Hong HL (2000) Microbial keratitis a late complication of penetrating keratoplasty. Trans R Soc Trop Med Hyg 94:315-317

4. Binder PS, Abel R, Polack FM, Kaufman HE (1975) Keratoplasty wound separations. Am J Ophthalmol 80:109-115

5. Shahinian L, Brown SI (1977) Postoperative complications with protruding monofilament sutures. Am J Ophthalmol 83:546-548

6. Nirankari VS, Karesh JW, Richards RD (1983) Complications of exposed monofilament sutures. Am J Ophthalmol 95:515-519

7. Khurshid GS, Fahy GT (2003) Endophthalmitis secondary to corneal sutures: series of delayed-onset keratitis requiring intravitreal antibiotics.

J Cataract Refract Surg 29:1370-1372

8. Henry CR, Flynn HW Jr, Miller D, Forster RK, Alfonso EC (2012) Infectious keratitis progressing to endophthalmitis: a 15-year-study of microbiology, associated factors, and clinical outcomes. Ophthalmology 119:2443-2449

9. Nucci C, Artini M, Pasmore M, Missiroli F, Costerton JW, Selan L (2005) A microbiological and confocal microscopy study documenting a slimeproducing Staphylococcus epidermidis isolated from a nylon corneal suture of a patient with antibiotic-resistant endophthalmitis. Graefe's Arch Clin Exp Ophthalmol 243:951-954 
10. Forstot FL, Abel R, Binder PS (1975) Bacterial endophthalmitis following suture removal and penetrating keratoplasty. Am J Ophthalmol 80:509-512

11. Muzaliha MN, Adil H, Ibrahim M, Shatriah I (2010) Candida glabrata endophthalmitis following penetrating keratoplasty in a patient with negative donor rim culture. BMC Ophthalmol 10:18

12. Confino J, Brown SI (1985) Bacterial endophthalmitis associated with exposed monofilament sutures following corneal transplantation. Am J Ophthalmol 99:111-113

13. Siganos C, Solomon A, Frucht-Pery J (1996) Microbial findings in suture erosion after penetrating keratoplasty. Ophthalmology 104:513-516

14. The Royal College of Ophthalmologists (2010) Cataract surgery guidelines., http://www.rcophth.ac.uk/core/core_picker/download.asp?id=544. Accessed 15 April 2013

15. Jackson H, Bosanquet R (1991) Should nylon corneal sutures be routinely removed? Br J Ophthalmol 75:663-664

16. Mowatt L, Butler $L$ (2004) Hazard of redundant corneal sutures: a safety message. J Cataract Refract Surg 30:1152

17. Dursun D, Forster RK, Feuer WJ (2003) Surgical technique for control of postkeratoplasty myopia, astigmatism, and anisometropia. Am J Ophthalmol 135:807-815

doi:10.1186/1869-5760-3-51

Cite this article as: Henry et al.: Delayed-onset endophthalmitis associated with corneal suture infections. Journal of Ophthalmic Inflammation and Infection 2013 3:51.

\section{Submit your manuscript to a SpringerOpen ${ }^{\circ}$ journal and benefit from:}

- Convenient online submission

- Rigorous peer review

- Immediate publication on acceptance

- Open access: articles freely available online

- High visibility within the field

- Retaining the copyright to your article 